\title{
Estratégia de protocolo hormonal baseado na antecipação de PGF2 $\alpha$ para melhorar a eficiência reprodutiva em vacas leiteiras submetidas a transferência de embriões em tempo fixo (TETF)
}

\author{
Hormone protocol strategy based on the anticipation of PGF2 $\alpha$ to improve the reproductive \\ efficiency of fixed time embryo transfer (FTET) in dairy cattle \\ Estrategia de protocolo hormonal basada en la anticipación de PGF2 $\alpha$ para mejorar la eficiencia \\ reproductiva en vacas lecheras que se someten a transferencia de embriones en tiempo fijo (TETF)
}

Recebido: 23/04/2021 | Revisado: 01/05/2021 | Aceito: 08/05/2021 | Publicado: 22/05/2021

\author{
Michael Nogueira de Medeiros \\ ORCID: https://orcid.org/0000-0001-9020-2818 \\ UNINTA Centro Universitário, Brasil \\ E-mail: michaelmedeirosvet@gmail.com \\ Felipe Venceslau Câmara \\ ORCID: https://orcid.org/0000-0002-2089-5206 \\ Universidade Potiguar, Brasil \\ E-mail: felipe.camara@unp.br \\ Glaucinete Borges de Souza \\ ORCID: https://orcid.org/0000-0001-9387-8688 \\ UNINTA Centro Universitário, Brasil \\ E-mail:glaucinhaborges@hotmail.com \\ André Luiz de Medeiros \\ ORCID: https://orcid.org/0000-0001-6787-1677 \\ Faculdade Cisne de Quixadá, Brasil \\ E-mail: alnmedeiros@bol.com.br \\ Deborah de Melo Magalhães-Padilha \\ ORCID: https://orcid.org/0000-0002-6428-8627 \\ Universidade Potiguar, Brasil \\ E-mail:dmmvet@hotmail.com
}

\begin{abstract}
Resumo
Esse estudo objetivou comparar dois protocolos hormonais para transferência de embriões em tempo fixo (TETF) em vacas de leite baseados no momento da aplicação de PGF2 $\alpha$. Um total de 2.172 vacas mestiças Bos indicus foram utilizadas. De acordo com o protocolo de sincronização das receptoras de embriões, as vacas foram divididas em dois tratamentos: o Convencional e o MMSINCRO (tratamento teste). O protocolo Convencional consistiu na inserção de um dispositivo contendo progesterona e administração de benzoato de estradiol no Dia 0 . No Dia 8 , a progesterona foi removida e aplicado PGF2 $\alpha$, eCG e cipionato de estradiol. No Dia 10, os animais receberam GnRH. A TETF foi realizada no Dia 17. O MMSINCRO consistiu na inserção da progesterona e administração de benzoato de estradiol no Dia 0 . No Dia 7, animais receberam PGF2 $\alpha$. No Dia 9, a progesterona foi removida e os animais receberam eCG e cipionato de estradiol. No dia 11, foi aplicado GnRH. A TETF foi realizada no Dia 18. A taxa de concepção das receptoras do tratamento MMSINCRO (52\%) foi significativamente superior a do protocolo Convencional (33\%). A avaliação qualitativa do corpo lúteo mostrou uma melhor qualidade no tratamento MMSINCRO. Dessa forma, foi possível concluir que para TETF em vacas leiteira, aconselha-se a utilização do protocolo MMSINCRO nas receptoras, o qual foi capaz de aumentar a taxa de concepção. Esse achado proporciona uma melhora na eficiência reprodutiva de bovinos leiteiros, e consequentemente, em uma maior produção de leite e derivados nas fazendas de vacas leiteiras.
\end{abstract}

Palavras-chave: Protocolo hormonal; Transferência de embrião em tempo fixo; PGF2 $\alpha$; Taxa de concepção.

\begin{abstract}
This study aimed to compare two hormonal protocols for fixed-time embryo transfer (FTET) in dairy cows based on the moment of PGF2 $\alpha$ application. A total of 2,172 crossbred Bos indicus cows were used. According to the embryo recipient synchronization protocol, the cows were divided into two treatments: Conventional and MMSINCRO (test treatment). The Conventional protocol consisted of inserting a device containing progesterone and administering estradiol benzoate on Day 0. On Day 8, progesterone was removed and PGF2 $\alpha$, eCG and estradiol cypionate were applied. On Day 10, the animals received GnRH. FTET was performed on Day 17. The MMSINCRO protocol
\end{abstract}


consisted of the insertion of progesterone and administration of estradiol benzoate on Day 0. On Day 7, animals received PGF2 $\alpha$. On Day 9, the progesterone was removed and the animals received eCG and estradiol cypionate. On Day 11, GnRH was applied. The FTET was performed on Day 18. The conception rate of the MMSINCRO treatment recipients (52\%) was significantly higher than that of the Conventional protocol (33\%). The qualitative evaluation of the corpus luteum showed a better quality in the MMSINCRO treatment. Thus, it was possible to conclude that for FTET in dairy cows, it is advisable to use the MMSINCRO protocol in the recipients, which was able to increase the conception rate. This finding provides an improvement in the reproductive efficiency of dairy cattle, and consequently, a greater production of milk and dairy products on dairy farms.

Keywords: Hormonal protocol; Fixed time embryo transfer; PGF2 $\alpha$; Conception rate.

\section{Resumen}

Este estudio tuvo como objetivo comparar dos protocolos hormonales para la transferencia de embriones en tiempo fijo (TETF) en vacas lecheras en función del momento de aplicación de PGF2 $\alpha$. Se utilizaron un total de 2.172 vacas cruzadas Bos indicus. Según el protocolo de sincronización del receptor de embriones, las vacas se dividieron en dos tratamientos: convencional y MMSINCRO (tratamiento de prueba). El protocolo convencional consistió en insertar un dispositivo que contenía progesterona y administrar benzoato de estradiol el día 0 . El día 8 se eliminó la progesterona y se aplicaron PGF2 $\alpha$, ECG y cipionato de estradiol. El día 10, los animales recibieron GnRH. El TETF se realizó el día 17. MMSINCRO consistió en la inserción de progesterona y la administración de benzoato de estradiol el día 0 . El día 7, los animales recibieron PGF2 $\alpha$. El día 9, se eliminó la progesterona y los animales recibieron eCG y cipionato de estradiol. El día 11 se aplicó GnRH. El TETF se realizó el día 18. La tasa de concepción de los receptores del tratamiento MMSINCRO (52\%) fue significativamente mayor que la del protocolo convencional (33\%). La evaluación cualitativa del cuerpo lúteo mostró una mejor calidad en el tratamiento con MMSINCRO. Así, se pudo concluir que para TETF en vacas lecheras, es recomendable utilizar el protocolo MMSINCRO en las receptoras, lo que logró incrementar la tasa de concepción. Este hallazgo proporciona una mejora en la eficiencia reproductiva del ganado lechero y, en consecuencia, una mayor producción de leche y productos lácteos en las granjas lecheras.

Palabras clave: Protocolo hormonal; Transferencia de embriones por tiempo fijo; PGF2 $\alpha$; Tasa de concepción.

\section{Introdução}

A pecuária bovina se destaca como uma atividade econômica que ocupa a maior área de terra. Atualmente, o Brasil possui o segundo maior rebanho bovino efetivo do mundo (Rossi et al., 2017). A produção de gado leiteiro é uma atividade social e economicamente muito importante em todo o mundo, principalmente devido ao aumento do interesse por leite $\mathrm{e}$ derivados (Assis et al., 2016). Para uma produção de leite eficiente, é necessário um controle sanitário rigoroso, assim como o monitoramento reprodutivo dos animais. Atualmente, o uso de biotecnologias reprodutivas em bovinos tem melhorado significativamente o potencial reprodutivo dessa espécie (Baruselli et al., 2011). Dentre essas biotecnologias, merece destaque a produção in vitro (PIVE) seguida da transferência de embriões em tempo fixo (TETF), que vem sendo constantemente estudada e com resultados progressivos ao longo dos anos (Gatea et al., 2018). Tendo em vista que a TETF tem uma grande importância na disseminação de animais de elevado valor zootécnico em vacas leiteiras, experimentos que busquem uma melhoria nas taxas de concepção de vacas receptoras de embrião seriam de grande valia, uma vez que levaria, inclusive, a um aumento na produção de leite e derivados.

Para maior praticidade e eficiência nos protocolos de TETF, é necessário o uso de protocolos hormonais nas fêmeas receptoras de embriões, que permitam a sincronização dos animais. Em bovinos, vários protocolos de sincronização hormonal em vacas receptoras foram desenvolvidos na tentativa de melhorar as taxas de concepção após a transferência de embriões oriundos de fertilização in vitro (FIV) (Luedke et al., 2019). A maioria dos protocolos atuais para TETF em vacas receptoras de embriões são baseados em dispositivo de progesterona, associado a aplicações de gonadotrofina coriônica equina (eCG), prostaglandina F2 $\alpha$ (PGF2 $\alpha$ ), estradiol e análogos do hormônio liberador de gonadotrofina (GnRH) (Medalha et al., 2015). Nestes protocolos hormonais, a PGF2 $\alpha$ é utilizada quando o dispositivo de progesterona é removido. Tendo em vista que aqueles protocolos que utilizam PGF2 $\alpha$ na remoção do dispositivo de progesterona ainda não alcançaram resultados satisfatórios, hipotetizamos neste estudo que a aplicação de PGF2 $\alpha 48 \mathrm{~h}$ antes da remoção do dispositivo de progesterona melhora a eficiência dos protocolos TETF em vacas leiteiras por permitir um melhor desempenho do eCG e do cipionato de 
estradiol que também são utilizados no protocolo.

Apesar dos diversos estudos utilizando protocolos hormonais para receptores na técnica FETF, a eficiência desses protocolos para vacas leiteiras ainda é baixa, necessitando de mais estudos, principalmente sobre o melhor momento para administração de PGF2 $\alpha$. Esses estudos teriam como objetivo melhorar as taxas de concepção em vacas leiteiras e, consequentemente, aumentar a produção de leite e derivados. Assim, o objetivo deste estudo foi desenvolver um protocolo de indução da ovulação para vacas leiteiras receptoras, baseado no momento da aplicação do PGF2 $\alpha$, que permita melhorar as taxas de concepção nos protocolos do TETF.

\section{Metodologia}

\subsection{Local, animal e manejo}

Esse estudo foi realizado em 3 fazendas, a saber: Santana (Santana do Acaraú-Ceará-Brasil - Latitude: $2^{\circ}$ 53' 23" Sul, Longitude: $40^{\circ} 6^{\prime} 31^{\prime \prime}$ Oeste), Nova esperança (Cariré-Ceará-Brasil - Latitude: $3^{\circ}$ 57' 2" Sul, Longitude: 40 28' 21" Oeste) e Thanks (Umirim-Ceará-Brasil - Latitude: $3^{\circ} 41^{\prime} 7^{\prime \prime}$ Sul, Longitude: $39^{\circ} 20^{\prime} 38^{\prime \prime}$ Oeste). Para tanto, vacas leiteiras primíparas e pluríparas mestiças Bos indicus (fêmeas 3/4 e 5/8 girolando) $(n=2.172)$ foram utilizadas. As vacas foram mantidas em sistema extensivo que permitia o acesso a silagem de sorgo, sendo oferecido água e sal mineral a vontade. A seleção desses animais foi baseada no peso, escore de condição corporal adequado (ECC), período pós-parto, ciclos estrais normais e estado de saúde normal. As vacas em lactação foram utilizadas após um período de espera voluntário (PEV) médio de 45 dias (30 a 70 dias após o parto), e apenas as fêmeas com um ECC entre 2,5 e 3,5 em uma escala de 1 a 5 (Negreiros et al., 2020) foram selecionadas para receber os protocolos Convencional ou o protocolo MMSINCRO (tratamento teste) de sincronização de ovulação para transferência de embrião em tempo fixo (TETF).

\subsection{Design Experimental e realização da TETF}

Embriões frescos, provenientes de fertilização in vitro (FIV) com sêmen sexado para fêmeas, foram transferidos para vacas e novilhas receptoras, que receberam diferentes protocolos hormonais em um dia aleatório do ciclo estral (Dia 0). Um total de 851 receptoras foram designadas para transferência de embrião usando o Protocolo Convencional (Pellegrino et al., 2016) de sincronização de ovulação (tratamento padrão) e 1.321 receptoras para transferência de embrião usando o MMSINCRO (tratamento teste) como protocolo de de sincronização de ovulação.

O Protocolo Convencional consistiu na inserção de dispositivo intravaginal contendo $1 \mathrm{~g}$ de progesterona (Primer® Tecnopec, São Paulo, Brasil) e administração (injeção intramuscular - im) de $2 \mathrm{mg}$ de benzoato de estradiol (RIC-BE® Tecnopec, São Paulo, Brasil) no Dia 0. No Dia 8, os dispositivos Primer® foram removidos e os animais receberam injeções im de 0,5 mg de cloprostenol (PGF2 $\alpha$-Estron® - Tecnopec, São Paulo, Brasil), 300 UI de gonadotrofina coriônica equina (Novormon®, MSD Animal Health, São Paulo, Brasil) e $1 \mathrm{mg}$ de cipionato de estradiol (ECP®; Zoetis, Rio Grande do Sul, Brasil). No dia 10, os animais receberam (injeção im) 4,2 $\mu \mathrm{g}$ de GnRH (Sincroforte ${ }^{\circledR}$ - Ouro Fino, São Paulo, Brasil). Vale ressaltar que todos os procedimentos deste protocolo foram realizados às $8 \mathrm{~h}$ da manhã (Figura 1). Antes da transferência do embrião (Dia 17), os ovários de cada receptora foram examinados usando palpação transretal e ultrassonografia com um ultrassom DP 2.200 com transdutor linear de $5 \mathrm{MHz}$ (Mindray, Pompéia, Brasil) para confirmar a presença e a qualidade do corpo lúteo (CL).

$\mathrm{O}$ tratamento MMSINCRO consistiu na inserção de dispositivo intravaginal contendo $1 \mathrm{~g}$ de progesterona (Primer® Tecnopec, São Paulo, Brasil) e administração (injeção im) de 2 mg de benzoato de estradiol (RIC-BE® - Tecnopec, São Paulo, Brasil) no Dia 0. No Dia 7, recebeu (injeção im) 0,5 mg de cloprostenol (PGF2 $\alpha$-Estron ${ }^{\circledR}$ - Tecnopec, São Paulo, Brasil). No dia 9, os dispositivos Primer® foram removidos e os animais receberam 300 UI de gonadotrofina coriônica equina 
(Novormon ${ }^{\circledR}$, MSD Animal Health, São Paulo, Brasil) e $1 \mathrm{mg}$ de cipionato de estradiol IM (ECP®; Zoetis, Rio Grande do Sul, Brasil). No dia 11, os animais receberam 4,2 $\mu \mathrm{g}$ de GnRH (Sincroforte ${ }^{\circledR}$, Ouro Fino, São Paulo, Brasil) (Figura 1B). Para este protocolo, os procedimentos nos Dias 0,7 e 9 foram realizados às $16 \mathrm{~h}$ e os procedimentos no Dia 11 às $8 \mathrm{~h}$ (Figura 1). Antes da transferência do embrião (Dia 18), os ovários de cada potencial foram examinados usando palpação transretal e ultrassonografia com um ultrassom DP 2.200 com transdutor linear de $5 \mathrm{MHz}$ (Mindray, Pompéia, Brasil) para confirmar a presença e a qualidade do corpo lúteo (CL).

Figura 1. Esquema dos protocolos Convencional e MMSINCRO para as vacas receptoras de embriões.

\section{PROTOCOLO CONVENCIONAL}

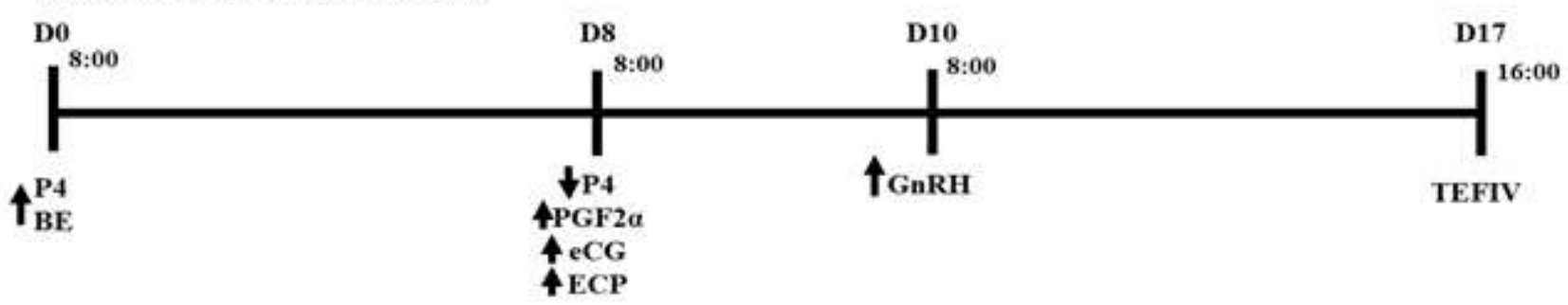

\section{MMSINCRO}

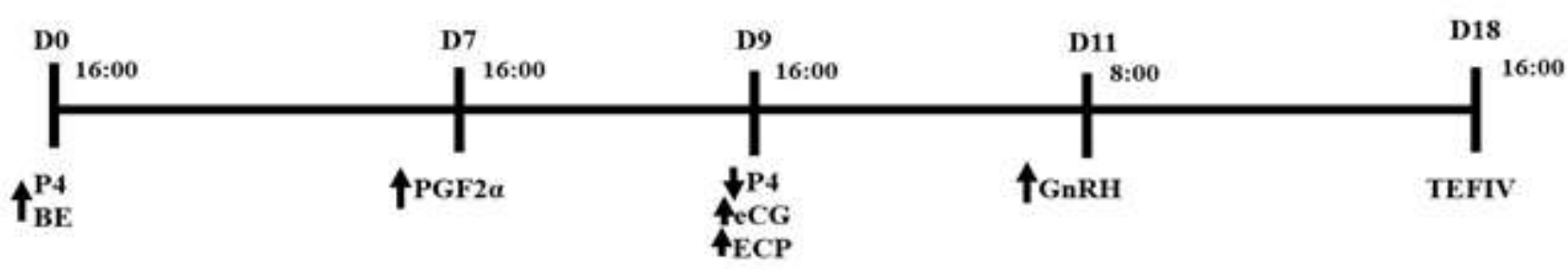

Fonte: Autores.

\subsection{Coleta de oócitos por ovum pick up (OPU)}

Os oócitos foram coletados de vacas Gir. O procedimento de aspiração folicular foi realizado com um aparelho de ultrassom DP 2200 (Mindray, Pompéia, Brasil) com transdutor microconvexo de 6,5 MHz conectado a uma agulha guia de biópsia $18 \mathrm{G}$ acoplada a tubos de centrífuga de $50 \mathrm{ml}$. A pressão de vácuo foi obtida com bomba WTA ajustada entre 90 e 95 mmHg. Para evitar movimentos peristálticos e desconforto às vacas, a anestesia peridural foi realizada com 2,5 ml de lidocaína a $2 \%$. A seguir, o transdutor foi levemente lubrificado com gel de ultrassom e inserido até o fundo de saco vaginal e, com o auxílio da manipulação transretal, os ovários foram posicionados para obter uma boa visualização na tela do ultrassom. Os folículos a serem aspirados foram posicionados ao longo do trajeto da linha de punção indicada na tela do ultrassom, sendo repetido o mesmo procedimento para todos os folículos visíveis em cada ovário. A lavagem da agulha e o meio de coleta de oócitos consistiram em DPBS (Modified Dulbeco - Nutricell) acrescido de 5 UI/ml de heparina sódica acrescido de $10 \%$ de soro fetal bovino (SFB).

\subsection{Maturação e fertilização in vitro}

No laboratório, o tubo contendo o material aspirado foi vertido em um filtro coletor de embriões (WTA®) e lavado com a mesma solução utilizada para aspiração folicular (PBS acrescido com Soro fetal bovino (SFB) a 1\% e Liquemina). Em seguida, os complexos cumulus oócito (CCOs) foram contados e avaliados de acordo com a qualidade. Os CCOs foram 
classificados de acordo com sua morfologia (número de camadas de células do cumulus e aspecto do citoplasma) em Graus I, II e III (Pujo, López-Béjar, \& Paramio, 2004).

Após a classificação, os CCOs foram lavados em solução (Vitrogen®) suplementado com 10\% de soro fetal bovino (SFB-Gibco) e cultivados em meio de maturação (Vitrogen®) sob óleo mineral, a uma temperatura de $38,5^{\circ} \mathrm{C}$ e atmosfera controlada de gás $(5 \% \mathrm{CO} 2+5 \% \mathrm{O} 2+90 \% \mathrm{~N} 2)$ por $24 \mathrm{~h}$.

Após IVM, os CCOs foram lavados usando meio de fertilização (Vitrogen®). Para fertilizar os oócitos, foi utilizado espermatozóide sexado para fêmea (portador do cromossomo X) obtido de um touro holandês. Para a FIV, palhetas congeladas contendo 2 x 106 espermatozoides foram descongelados por 30 segundos em banho-maria a $37^{\circ} \mathrm{C}$. Os espermatozoides foram lavados por centrifugação através de gradiente de Percoll de 45 a $90 \%$ a 600 g por 5 min. A motilidade e a concentração espermática foram avaliadas e $1 \times 10^{6}$ espermatozoides móveis $/ \mathrm{mL}$ foram adicionados a cada gota de fertilização. A fertilização ocorreu durante as 18 e $22 \mathrm{~h}$ de incubação nas mesmas condições de temperatura e atmosfera.

\subsection{Transferência de embriões}

Após a FIV, as células do cumulus foram removidas dos presumíveis zigotos. Os presumíveis zigotos foram transferidos para gotas de $80 \mu \mathrm{L}$ de meio de cultivo embrionário (Vitrogen®) sob a mesma temperatura e condições atmosféricas que aquelas usadas para a FIV. Os embriões foram mantidos nessas condições até o momento da transferência para as receptoras.

A osmolalidade do meio de cultivo foi mantida a 270 a $280 \mathrm{mOsm}$ e o $\mathrm{pH}$ foi de 7,4. No dia 7, os embriões foram classificados de acordo com os critérios da International Embryo Technology Society, e apenas embriões de graus I ou II foram considerados para transferência. Cada embrião foi inserido em uma palheta de $0,25 \mathrm{ml}$, transportado por uma curta distância até a fazenda em um transportador de embriões (TED, Ribeirão Preto, SP, Brasil) a uma temperatura de $38,5^{\circ} \mathrm{c}$ e, a seguir, transferido via cervical de forma não cirúrgica para o corno uterino ipsilateral ao local do CL de cada receptora previamente sincronizada. Apenas embriões que estavam nos estágios de blastocisto inicial (BI), blastocisto (BL) ou blastocisto expandido (BX) foram transferidos para as receptoras.

\subsection{Avaliação qualitativa do corpo lúteo}

No momento da transferência dos embriões para as receptoras, uma avaliação qualitativa do corpo lúteo (CL) através de ultrassom foi realizada, baseada no tamanho, na hiperecogenicidade da imagem e consistência a palpação retal. Vale ressaltar que, para ambos os tratamentos (convencional e MMSINCRO), somente receptoras com CL $\geq 13 \mathrm{~mm}$ de diâmetro receberam embrião. Além disso, foi observado qualitativamente o fluxo sanguíneo do corpo lúteo com a utilização do Doppler pulsado e transdutor de alta resolução.

\subsection{Taxa de concepção}

As fêmeas foram avaliadas por ultrassonografia transretal (DP 10 com transdutor linear de 6,5 MHz; Mindray, Shenzhen, China) após 23 dias da transferência do embrião (embrião cultivado por 7 dias) para determinar seu estado de gestação. A taxa de concepção foi calculada pelo número de vacas gestantes sobre o número de vacas inovuladas com embriões, em um período de 30 dias.

\subsection{Análise estatística}

Quando apropriado, os testes de qui-quadrado ou exato de Fisher foram usados para avaliar as variáveis em percentuais (número de oócitos recuperados, embriões transferidos e taxa de concepção) entre os tratamentos. Diferenças 
foram consideradas significativas quando $\mathrm{P}<0,05$.

\section{Resultados e Discussão}

O número de oócitos recuperados, embriões transferidos, percentual de embriões transferidos e taxa de concepção em vacas receptoras utilizando o Protocolo Convencional e o MMSINCRO para TETF estão mostrados na Tabela 1. Após o diagnóstico de gestação por ultrassonografia, as receptoras que receberam o protocolo MMSINCRO apresentaram um percentual de concepção superior $(\mathrm{P}<0,05)$ aquelas do tratamento Convencional (52\% x 33\%, respectivamente). Os demais parâmetros avaliados nesta tabela não mostraram diferenças significativas. Após uma avaliação qualitativa baseado na hiperecogenicidade do CL na imagem do ultrassom. e na consistência na palpação retal, pôde-se verificar um CL de melhor qualidade nos animais submetidos ao MMSINCRO quando comparado aos que receberam o protocolo Convencional. Além disso, ao se observar qualitativamente o fluxo sanguíneo do corpo lúteo com a utilização do Doppler, pode-se verificar uma maior vascularização nos CL oriundos das receptoras que utilizaram o protocolo MMSINCRO. Por outro lado, nas receptoras tratadas com o protocolo convencional, alguns CL cavitário foram observados (Figura 2A e 2B).

Tabela 1. Número de embriões transferidos, percentual de embriões transferidos e taxa de concepção em vacas receptoras utilizando o Protocolo Convencional e o MMSINCRO em fêmeas receptoras para TETF.

\begin{tabular}{ccccc}
\hline Tratamentos & $\begin{array}{c}\text { Total de } \\
\text { animais }\end{array}$ & $\begin{array}{c}\text { Número de } \\
\text { embriões } \\
\text { transferidos(n) }\end{array}$ & $\begin{array}{c}\text { Percentual de embriões } \\
\text { transferidos }\end{array}$ & $\begin{array}{c}\text { Taxa de } \\
\text { concepção }\end{array}$ \\
\hline $\begin{array}{c}\text { Protocolo } \\
\begin{array}{c}\text { Convencional } \\
\text { MMSINCRO }\end{array}\end{array}$ & 851 & 865 & $24 \%^{\mathrm{a}}(865 / 3,643)$ & $33 \%^{\mathrm{a}}$ \\
& 1321 & 974 & $26 \%^{\mathrm{a}}(974 / 3,756)$ & $\begin{array}{c}(284 / 851) \\
52 \%{ }^{\mathrm{b}} \\
(690 / 1321)\end{array}$ \\
\hline
\end{tabular}

a,b Dentro de cada coluna, tratamentos com letras diferentes diferem $(\mathrm{p}<0,05)$ entre si. Fonte: Autores.

Figura 2. Imagens de ultrassom com doppler ilustrando a morfoecogenicidade do corpo lúteo (CL), na qual se observa em A um CL oriundo de receptoras sincronizadas com o protocolo MMSINCRO e em B um corpo lúteo oriundo de receptoras sincronizadas com o protocolo Convencional. Pode-se verificar que o CL da figura A apresenta-se bastante irrigado, demonstrando excelente qualidade e em B um CL com uma cavidade, apresentando uma qualidade inferior ao CL da figura 2A.
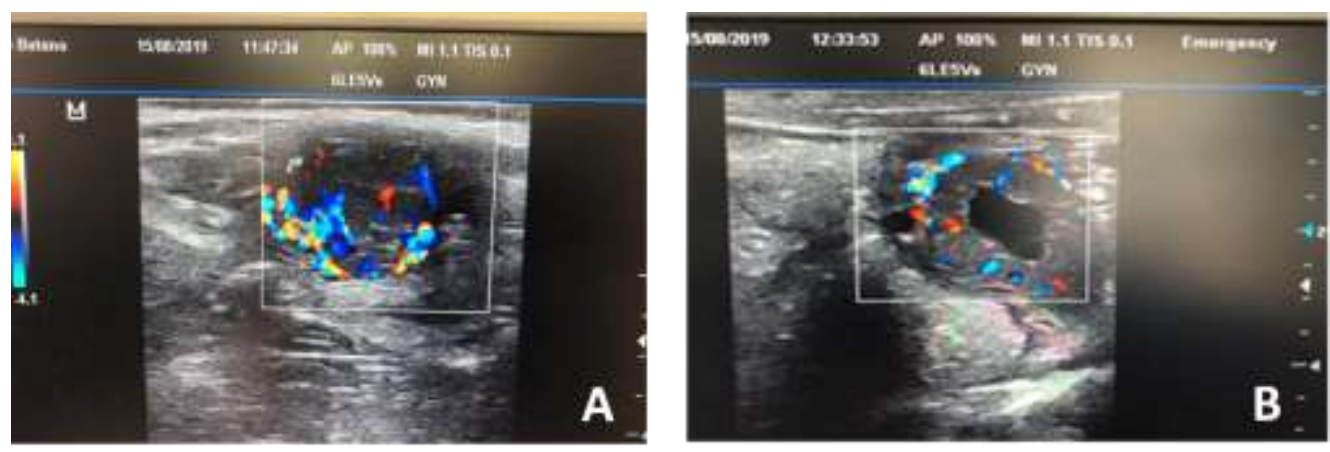

Fonte: Autores.

Esse artigo mostra, pela primeira vez, o efeito da antecipação da PGF2 $\alpha$ em um protocolo de sincronização de receptoras em programas de TETF em bovinos de leite. Sabe-se que a técnica de TETF tem sido uma importante ferramenta 
para na disseminação de animais de alta qualidade genética, o que consequentemente, em vacas leiteiras, leva a uma melhoria na produção de leite e derivados (Baruselli et al., 2011).

No presente estudo, quando a PGF2 $\alpha$ foi antecipada no protocolo de sincronização das receptoras para TETF, ocorreu um aumento na resposta ovulatória das fêmeas receptoras e, consequentemente, um aumento na taxa de concepção das vacas e melhorou a qualidade dos corpos lúteos formados. Nas maiorias dos trabalhos publicados com protocolos tradicionais de TETF em bovinos, as taxas de concepção variam entre 30 a 45 \% (Morais et al., 2013; Sá Filho et al., 2009). Já a taxa de concepção obtida no presente experimento com o protocolo MMSINCRO foi de $52 \%$. Esse aumento resulta em um grande ganho econômico para a fazenda. A PGF2 $\alpha$ e seus análogos sintéticos são comumente utilizados em protocolos hormonais de bovinos, especialmente quando se utiliza programas de transferência de embriões em tempo fixo (Sauls-Hiesterman, Voelz, \& Stevenson, 2020). A utilização desse hormônio tem como um dos principais efeitos a indução da luteólise, ou seja, destruição do corpo lúteo (Gaebler et al., 2015; Barreiros et al., 2006). Essa ação luteolítica em protocolos hormonais visa a diminuição da progesterona antes da aplicação do eCG, GnRH e cipionato de estradiol, visando uma melhor ação desses hormônios utilizados, e consequentemente, a ovulação. Dessa forma, acredita-se que a antecipação da PGF2 $\alpha$ testada no presente estudo, tornou a resposta do eCG mais eficaz. Ou seja, proporcionou que o eCG aumentasse o seu poder de desenvolvimento folicular, o que proporcionou que a sua ação (semelhante a ação de hormônio folículo estimulante-FSH, melhorasse na taxa de ovulação e consequentemente, uma melhora na qualidade do CL formado. Uma vez que a progesterona, produzida pelo CL, é essencial no processo de implantação e desenvolvimento embrionário (Lucy, 2019), percebeu-se nesse experimento que, quanto melhor a qualidade do CL nos animais receptores, maior a taxa de concepção dos animais.

No presente experimento, no protocolo convencional a progesterona foi retirada no Dia 8, enquanto no protocolo MMSINCRO a progesterona foi retirada no Dia 9. Sabe-se que nos protocolos hormonais convencionais, diversos trabalhos têm realizado a retirada da progesterona no Dia 9 (Pessoa, Pereira \& Melo, 2014) e outros no Dia 8 (Santos et al., 2006), não havendo diferença na taxa de concepção entre esses protocolos na taxa de concepção. Dessa forma, apesar da diferença de 1 dia no momento da retirada do dispositivo de progesterona entre os protocolos testados no presente experimento, acredita-se que as maiores taxas de concepção no protocolo MMSINCRO comparado ao protocolo convencional utilizado nesse estudo, deve-se, de fato, a antecipação da PGF2 $\alpha$.

As elevadas taxas de concepção encontradas nesse experimento com sêmen sexado em ambos os tratamentos, principalmente no grupo de receptoras sincronizadas com o MMSINCRO, também pode ser devido a utilização do eCG como um estimulante do desenvolvimento folicular. Segundo Ayres et al., (2007), quando usado em protocolos de sincronização do estro e ovulação em bovinos, esse hormônio estimula o crescimento folicular e o aumento do diâmetro do CL. Este fato pode ser explicado, tendo em vista que o CL é formado pela transformação das células foliculares em células luteínicas. Dessa forma, como um maior diâmetro de CL está associado com uma maior produção de progesterona (Núñez -Olivera et al., 2014), isso pode explicar as altas taxas de concepção encontradas no presente experimento. Entretanto, Ayres et al., (2007), demonstraram que, em animais com um ECC desejável (entre 3 e 4), a utilização do eCG não diferenciou nas taxas de concepção e nem proporcionou maiores diâmetros foliculares, sendo este hormônio considerado dispensável, uma vez que eleva o custo do tratamento.

Outro hormônio utilizado em ambos os tratamentos do presente experimento foi o Hormônio Liberador de Gonadotrofinas $(\mathrm{GnRH})$ com o intuito de induzir a ovulação. Apesar de alguns trabalhos não demonstrarem o efeito benéfico desse hormônio em protocolos de sincronização do estro e da ovulação (Leite et al., 2006; Oliveira et al., 2020), este hormônio proporcionou uma melhora na taxa de prenhes devido a uma melhora nas taxas de ovulação em vacas de leite (Mee, Stevenson, \& Scoby, 1990). 


\section{Conclusão}

Dessa forma, é possível concluir que para TETF em vacas leiteira, aconselha-se a utilização do MMSINCRO baseado na antecipação da PGF2 $\alpha$, que foi capaz de aumentar a taxa de concepção em vacas de leite. Esse achado proporciona uma melhora na eficiência reprodutiva de bovinos leiteiros, e consequentemente, em uma maior produção de leite e derivados nas fazendas de vacas leiteiras, visando um aumento no perfil econômico do país.

\section{Agradecimentos}

Os autores agradecem ao Conselho Nacional de Desenvolvimento Científico e Tecnológico (CNPq) pelo apoio a esta pesquisa. Além disso, os autores também agradecem aos proprietários das fazendas por permitirem o desenvolvimento da pesquisa. Os autores agradem a empresa Michael Medeiros pelo suporte durante o experimento.

\section{Referências}

Assis, J., Ferreira, J. D., Martins, H. H., \& Schneider, M. B. (2016). Cadeia produtiva do leite no brasil no contexto do comércio internacional. Revista de Ciências Empresariais da UNIPAR, 17(1), 63-93.

Ayres, H., Marques, M. O., Silva, R. C. P., Rodrigues, C. A., Ferreira, R. M, \& Baruselli, P. S. (2007). Influência do uso de eCG em diferentes períodos pós parto e do escore de condição corporal na taxa de prenhez de vacas nelore inseminadas em tempo fixo. Acta Scientiae Veterinariae, $35(3)$ : s1113.

Barreiros, T. R. R., Blaschi, W., Borsato, E. A., Ludwig, H. E., Silva, D. R. M., Seneda, M.M. (2006). Comparação das taxas de prenhez entre receptoras com corpos lúteos cavitários ou compactos após protocolos de sincronização com clorprostenol ou transferência de embriões em tempo fixo. Semina: Ciências Agrárias, 27(4), 657-664

Baruselli, P. L., Ferreira, R. M., Sales, J. N. S., Gimenes, L. U., Sá Filho, M. F., Martins, C. M., Rodrigues, C. A., \& Bó, G. A. (2011). Timed embryo transfer programs for management of donor and recipient cattle. Theriogenology, 76(9), 1583-1593.

Gaebler, E., Eigenmann, U., Bruckmaier, R., \& Bleul, U. (2015). Fate of follicular ovarian cysts in early postpartum dairy cows treated with PRID/PGF or PRID/PGF plus eCG. Tierarztl Prax Ausg Grosstiere Nutztiere, 43(6), 331-9.

Gatea, A. O., Smith, M. F., Pohler, K. G., Egen, T., Pereira, M. H. C., Vasconselos, J. L. M., Lawrence, J. C., \& Green, J.A. (2018). The ability to predict pregnancy loss in cattle with ELISAs that detect pregnancy associated glycoproteins is antibody dependent. Theriogenology, 108(1), 269-276.

Leite, P. A. G., Carvalho, G. R., Rodrigues, M. T., Ruas, J.R.M., Amorim, E. A. M., \& Maffili, V. V. (2006). Induction of the out-of-season ovulation (with $\mathrm{LH}$ and $\mathrm{GnRH}$ ) and estrus (with progesterone) in goats. Arquivo Brasileiro de Medicina Veterinária e Zootecnia, 58(3), .360-366.

Lucy, M. C. (2019). Symposium review: Selection for fertility in the modern dairy cow-Current status and future direction for genetic selection. Journal Dairy Science 102(4), 3706-3721.

Luedke, F. E., Lavach, F. L., Cassanta, F. G., Nunes, L. F. N., Schlotefeldt, C., Paiva, S. M., Santos, S. I., \& Neves, A. P. (2019). Aspectos da produção in vitro de embriões bovinos no Brasil - revisão. Pesquisa agropecuária gaúcha, 25(1/2), 120-132.

Medalha, A. G., Souza, M. I. L., Souza, A. S., Sá Filho, O. G., Queiroz, V. L. D., \& Costa Filho, L. C. C. (2015). Evaluation of intravaginal progesterone device, in until three uses, in fixed-time artificial insemination in "Bos indicus" females. Revista brasileira de saúde e produção animal, 16(2), 458-469.

Mee, M. O., Stevenson, J. S. \& Scoby, R. K. (1990). Influence of gonadotropin-releasing hormone and timing of insemination relative to estrus on pregnancy rates of dairy cattle at fi rst service. Journal of Dairy Science, 73(6), 1500-1507.

Morais, M. E. O., Mello, R. R. C., Ferreira, J. E., \& Mello, M. R. B. (2013). Comparação de diferentes métodos de manejo reprodutivo em receptoras de embrião bovino sobre a taxa de concepção. Revista Brasileira em Ciências Veterinárias, 20(2), 89-93.

Negreiros, M. P. M., Seugling, G. H. F., Almeida, A. B. M., Hidalgo, M. M. T., Martins, M. I. M., Blaschi, W., \& Barreiros, T. R. R. (2020). Influence of nutritional and ovarian parameters on pregnancy rates of Nelore cows artificially inseminated at fixed time. Research, Society and Development, 9(9), e907998091.

Núñez-Olivera, R., Castro, T., García-Pintos, C., Bó, G., Piaggio, J., \& Menchaca, A. (2014). Ovulatory response and luteal function after eCG administration at the end of a progesterone and estradiol' based treatment in postpartum anestrous beef cattle. Animal Reproduction Science, 146(3-4), 111-116.

Oliveira, F. A., Almeida, I. C., Penitente Filho, J. M., \& Torres, C. A. A. (2020). Estradiol e GNRH na sincronização do estro e indução da ovulação de vacas mestiças. Revista Caatinga, 33(3), 815-823.

Pellegrino, C. A. G., Morotti, F., Untura, R. M., Pontes, J. H. F., Pellegrino, M. F. O., Campolina, J. P., Seneda, M. M., Barbosa, F. A., \& Henry, M. (2016). Use of sexed sorted semen for fixed-time artificial insemination or fixed-time embryo transfer of in vitro produced embryos in cattle. Theriogenology, $86(1)$, 888-893.

Pessoa, A. B. C. M., Pereira, E. T. N., Melo, M. I. V. (2014). Influência do local de inovulação e do tamanho de corpo lúteo sobre a taxa de prenhez em programa de transferência de embriões bovinos em tempo fixo. Revista Brasileira de Reprodução Animal, 38(4), $237-241$. 
Research, Society and Development, v. 10, n. 6, e10510615382, 2021

(CC BY 4.0) | ISSN 2525-3409 | DOI: http://dx.doi.org/10.33448/rsd-v10i6.15382

Pujo, M., López-Béjarb, M., \& Paramio, M. T. (2004). Developmental competence of heifer oocytes selected using the brilliant cresyl blue (BCB) test. Theriogenology, 61 (4), 735-744.

Rossi, G., De Leo, G. A., Pongolini, S., Natalini, S., Zarenghi, L., Ricchi, M., \& Bolzoni, L. (2017). The potential role of direct and indirect contacts on infection spread in dairy farm networks. Plos Computational Biology, 13(1), e1005301.

Sá Filho, O. G., Meneghetti, M., Peres, R. F. G., Lamb, G. C., \& Vasconcelos, J. L. M. (2009). Fixed-time artificial insemination with estradiol and progesterone for Bos indicus cows II: Strategies and factors affecting fertility. Theriogenology, 72(2), 210-218.

Sauls-Hiesterman, J. A., Voelz, B. E., \& Stevenson, J. S. (2020). A shortened resynchronization treatment for dairy cows after a nonpregnancy diagnosis. Theriogenology, 141(1), 105-112. 